\title{
Rancang Bangun Aplikasi Pendataan Alumni SMA Negeri 6 Palembang Menggunakan CodeIgniter
}

\author{
Ahmad Farisi*1, Sudiadi $^{2}$ \\ ${ }^{1,2}$ Universitas Multi Data Palembang; Jl. Rajawali No. 14 Palembang, 0711-376400 \\ ${ }^{3}$ Program Studi Sistem Informasi, Fakultas Ilmu Komputer dan Rekayasa Universitas Multi \\ Data Palembang, Palembang \\ e-mail: *1ahmadfarisi@mdp.ac.id, ${ }^{2}$ sudiadi@mdp.ac.id
}

\begin{abstract}
Abstrak
Dalam perjalanan 40 tahun berdirinya SMA Negeri 6 Palembang sejak tahun 1981, dibutuhkan sebuah media yang dapat menginventarisir data-data alumni yang telah tersebar sejak angkatan pertama hingga sekarang. Oleh karena itu, studi ini merancang bangun sebuah aplikasi pendataan alumni di SMA Negeri 6 Palembang. Studi ini dilakukan dengan menggunakan metodologi penelitian practism dengan research heuristics pada bidang software engineering yang menjawab rumusan masalah dengan mengembangkan perangkat lunak berdasarkan research perspective yang dilakukan pada tahap pra-penelitian. Sementara itu, pengembangan sistem dilakukan dengan menggunakan metode Kanban pada pendekatan Agile Development Cycle. Pada tahap pra-penelitian, studi ini mengumpulkan data dengan melakukan wawancara kepada pihak SMA Negeri 6 Palembang terkait kebutuhan pengembangan apllikasi. Aplikasi ini dikembangkan pada platform web dengan framework CodeIgniter dan custom core system class yang dibangun secara custom. Aplikasi ini memiliki 2 aktor yang terdiri dari alumni dan admin. Fitur-fitur aplikasi ini adalah pengelolaan alumni yang meliputi data identitas, pendidikan, dan pekerjaan alumni. Studi ini melakukan evaluasi aplikasi dengan menggunakan webuse method. Hasilnya menunjukkan nilai usability 0,79 untuk responden alumni dan nilai usability 0,76 untuk responden admin. Setelah diinterpretasikan, kedua nilai usability tersebut menunjukkan predikat baik.
\end{abstract}

Kata $\boldsymbol{k u n c i - a p l i k a s i , ~ a l u m n i , ~ c o d e i g n i t e r , ~ w e b u s e ~}$

\begin{abstract}
In the journey of 40 years since the establishment of SMA Negeri 6 Palembang on 1981, there is a need of a media that can manages the alumni data which has been spreaded since the first generation until now. Therefore, this study designed an application to collect alumni data at SMA Negeri 6 Palembang. This study was conducted using a practical research methodology with research heuristics in the field of software engineering which answered the problem formulation by developing software based on a research perspective carried out at the preresearch stage. Meanwhile, system development is conducted using the Kanban method in the Agile Development approach. In the pre-research stage, this study collects data by conducting interviews regarding the needs of application development. This application is developed on a web platform with the CodeIgniter framework and its custom core system class. This application has 2 actors consisting of alumni and admin. The features are alumni data management which includes data, education, and occupation. This study conducted an evaluation to the application using the webuse method. The results show a usability value of 0.79 for alumni respondents and 0.76 for admin respondents. After being interpreted, the usability values show good predicates.
\end{abstract}

Keywords — application, alumni, codeigniter, webuse 


\section{PENDAHULUAN}

ntuk mendukung peningkatan kualitas pendidikan, diperlukan evaluasi kurikulum pendidikan

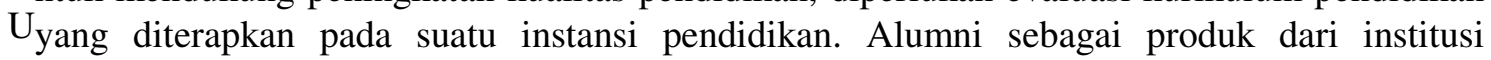
pendidikan dapat menggambarkan pencapaian visi dan misi dari instansi terkait. Upaya terbaik yang dapat dilakukan adalah dengan umpan balik dari peserta didik, khususnya peserta didik yang telah berhasil menyelesaikan pendidikannya di institusi terkait [1].

Pengelolaan data alumni dari instansi pendidikan merupakan salah satu contoh dari penerapan sistem informasi yang dapat membantu instansi pendidikan dalam mengelola data alumni secara lengkap melalui tersedianya layanan sistem informasi berbasis web [2]

SMA Negeri 6 Palembang merupakan salah satu Sekolah Menengah Atas unggulan yang berlokasi di Kota Palembang, Sumatera Selatan, tepatnya di Jl. Sersan Sani Basuki Rahmat Kelurahan Talang Aman Kecamatan Kemuning. SMA Negeri 6 Palembang didirikan di atas tanah seluas 10.000 M2 (1 Ha) dengan SK Pendirian Sekolah No.0219/6/1981 pada tanggal 4 Juli 1981. Saat ini, di tahun 2021, jumlah siswa SMA Negeri 6 Palembang mencapai 1058 orang (30 kelas) dan telah menjadi sekolah unggulan berbasis Imtaq [3].

Terhitung sejak tahun berdirinya 1981, SMA Negeri 6 Palembang telah memiliki 40 angkatan sampai dengan tahun 2021 ini. Artinya, telah ada 40 angkatan alumni dari tahun pembelajaran 1981/1982 hingga tahun pembelajaran 2020/2021. Sehubungan dengan itu, berdasarkan wawancara yang telah dilakukan dengan Bpk. Dedi Kustian, M.Pd. selaku Guru Ekonomi di SMA Negeri 6 Palembang, dibutuhkan sebuah media yang dapat menginventarisir data alumni yang telah tersebar sejak angkatan pertama hingga saat ini. Hal ini dibutuhkan karena saat ini SMA Negeri 6 Palembang belum memiliki media yang secara khusus dibuat untuk mengelola data alumni, khususnya media teknologi informasi. Adapun data-data alumni yang dibutuhkan setidaknya adalah data identitas alumni beserta data-data angkatan, pendidikan, dan pekerjaan, serta informasi kontak alumni.

Dalam beberapa studi sebelumnya, [4] mengembangkan sistem informasi pendataan alumni pada SMK Muhammadiyah Cerenti dengan terlebih dahulu merancang diagram use case, diagram activity, dan diagram sequence. Sistem yang dibangun berbasis web tersebut memiliki fitur pengelolaan data alumni yang dapat direkap secara keseluruhan, maupun berdasarkan angkatan maupun provinsi domisili tempat tinggal alumni. Sementara itu [5] merancang sistem informasi pendataan alumni pada SMA N 1 Kuantan Mudik berbasis web untuk menyelesaikan permasalahan pendataan alumni yang sebelumnya menggunakan pengisian buku besar data alumni saat alumni melegalisir ijazah. Sistem tersebut dibangun dengan terlebih dahulu merancang diagram use case dan diagram class. Dengan adanya sistem informasi pendataan alumni tersebut, bagian tata usaha SMA N 1 Kuantan Mudik dapat mengelola data alumni dengan lebih mudah hingga menyajikannya dalam bentuk laporan secara relevan, akurat, dan tepat waktu. Dalam studi lainnya, [6] merancang sistem informasi pendataan alumni pada STIE Prabumulih dengan framework CSS Bootstrap. Adapun sistem tersebut dibangun menggunakan model air terjun atau waterfall dengan alat bantu analisa dan perancangan seperti use case diagram, class diagram, dan activity diagram. Dengan adanya sistem tersebut, alumni STIE Prabumulih dapat memberikan informasi yang akurat serta memberikan kemudahan untuk STIE Prabumulih dalam mendata seluruh alumni yang telah tersebar.

Berdasarkan uraian di atas, didukung dengan beberapa studi-studi sebelumnya, studi ini melakukan pengembangan sebuah sistem pendataan alumni di SMA Negeri 6 Palembang yang dapat mengelola data-data alumni seperti identitas alumni beserta data-data angkatan, 
pendidikan, pekerjaan, dan informasi kontak alumni. Studi ini menggunakan Framework CodeIgniter yang merupakan Framework PHP yang dapat digunakan dalam pengembangan sistem berbasis web. Penggunaan Framework PHP juga telah banyak digunakan pada studi sebelumnya seperti yang telah dilakukan oleh [7] dan [8] yang menggunakan Framework CodeIgniter dalam mengembangkan sistem informasi manajemen donasi dan aplikasi tanda tangan digital berbasis web.

Oleh karena itu, yang menjadi rumusan masalah dalam studi ini adalah bagaimana merancang bangun sistem informasi pendataan alumni pada SMA Negeri 6 Palembang. Studi ini diharapkan memberikan manfaat, baik bagi penulis sebagai media penulisan studi-studi dan diseminasi penelitian, maupun bagi SMA Negeri 6 Palembang dalam pengelolaan data-data alumninya.

\section{METODE PENELITIAN}

Studi ini dilakukan dengan menggunakan metodologi penelitian practism dengan research heuristics pada bidang software engineering. Metode ini menjawab perumusan masalah dengan mengembangkan sistem atau perangkat lunak berdasarkan research perspective yang dilakukan pada tahap pra-penelitian [9]. Adapun langkah-langkah metodologi penelitian ini secara umum adalah perumusan masalah, studi literatur, penyusunan instrumen penelitian, pengumpulan data, analisis data, pengembangan dan evaluasi sistem, dan penarikan kesimpulan.

\subsection{Metode Pengembangan Sistem}

Sementara itu, pengembangan sistem yang dilakukan dalam studi ini menggunakan pendekatan Agile Development Cycle dengan metode Kanban. Kanban merupakan sistem alur kerja yang biasa digunakan dalam proses manufaktur dan pengembangan perangkat lunak untuk meningkatkan efisiensi dan produktivitas. Namun kanban juga dapat digunakan dengan efektivitas yang sama untuk menjaga segala bentuk proyek agar tetap pada jalurnya atau sebagai alat untuk manajemen waktu pribadi. Kanban dikembangkan pertama kali pada akhir tahun 1940 oleh Toyota untuk mempersingkat dan mendukung proses manufaktur yang "tepat sebelum deadline", metodologi kanban kemudian diadopsi oleh David Anderson sebagai sebuah alat dalam metodologi Agile [10].

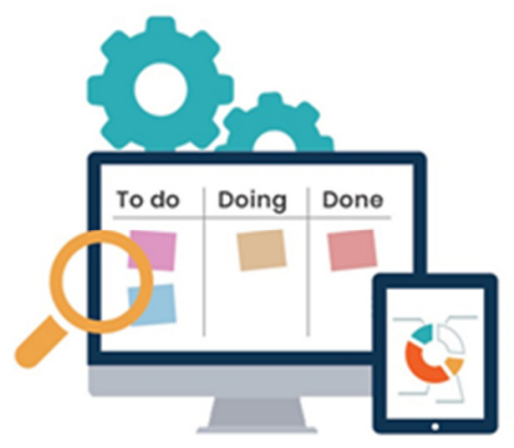

Gambar 1. Ilustrasi Metode Kanban Dalam Pendekatan Agile Development Cycle [11]

Pada intinya, kanban merupakan sistem yang memvisualisasikan perkerjaan. Inti dari metodologi kanban adalah pembuatan "board" dimana kita meletakkan "card" atau kartu yang berisi tugas yang perlu diselesaikan. Dalam bentuk paling sederhana, sebuah Kanban Board 
berisi tiga kolom, yaitu yang perlu dikerjakan, yang sedang dikerjakan, yang telah dikerjakan [10].

\subsection{Webuse Method}

Pada tahap pra-penelitian, studi ini mengumpulkan data terlebih dahulu dengan melakukan wawancara kepada pihak SMA Negeri 6 Palembang terkait kebutuhan pengembangan sistem yang akan dilakukan. Tahapan ini mengumpulkan requirement dari sistem pendataan alumni yang akan dibangun.

Adapun instrumen penelitian berupa kuesioner digunakan untuk menguji sistem yang dibangun. Kuesioner ini disusun berdasarkan webuse method dengan skala 1 (sangat tidak setuju) sampai 7 (sangat setuju). Webuse method merupakan teknik analisis kuesioner yang melakukan evaluasi terhadap sebuah sistem yang berbasis web [12]. Metode ini berfokus pada pengembangan sistem evaluasi usability. Hasil dari webuse method adalah interpretasi nilai usability $(x)$ ke dalam bentuk predikat sangat buruk, buruk, cukup, baik, dan sangat baik.

\section{HASIL DAN PEMBAHASAN}

Berdasarkan uraian metode penelitian di atas, studi ini menghasilkan sebuah aplikasi pendataan alumni yang direncanakan berdasarkan studi terhadap beberapa penelitian terdahulu dan berdasarkan kebutuhan dari lokasi tempat studi kasus studi ini. Aplikasi ini dikembangkan pada platform web dengan framework CodeIgniter dan custom core system class yang dibuat secara custom. Pengembangan aplikasi dilakukan dengan menerapkan model kanban dalam pendekatan Agile Development Cycle, dan diuji menggunakan webuse method untuk mengetahui nilai usability-nya.

\subsection{Use Case Diagram}

Aplikasi pendataan alumni SMA Negeri 6 Palembang ini dikembangkan dengan terlebih dahulu merancang diagram use case untuk memetakan behaviour dari sistem. Diagram use case digunakan untuk mengambarkan interaksi antara pengguna sistem (actor) dengan kasus (use case) yang disesuaikan dengan langkah-langkah (scenario) yang telah ditentukan [13]. Diagram use case dari aplikasi yang dikembangkan dalam studi ini terdapat pada Gambar 2. 


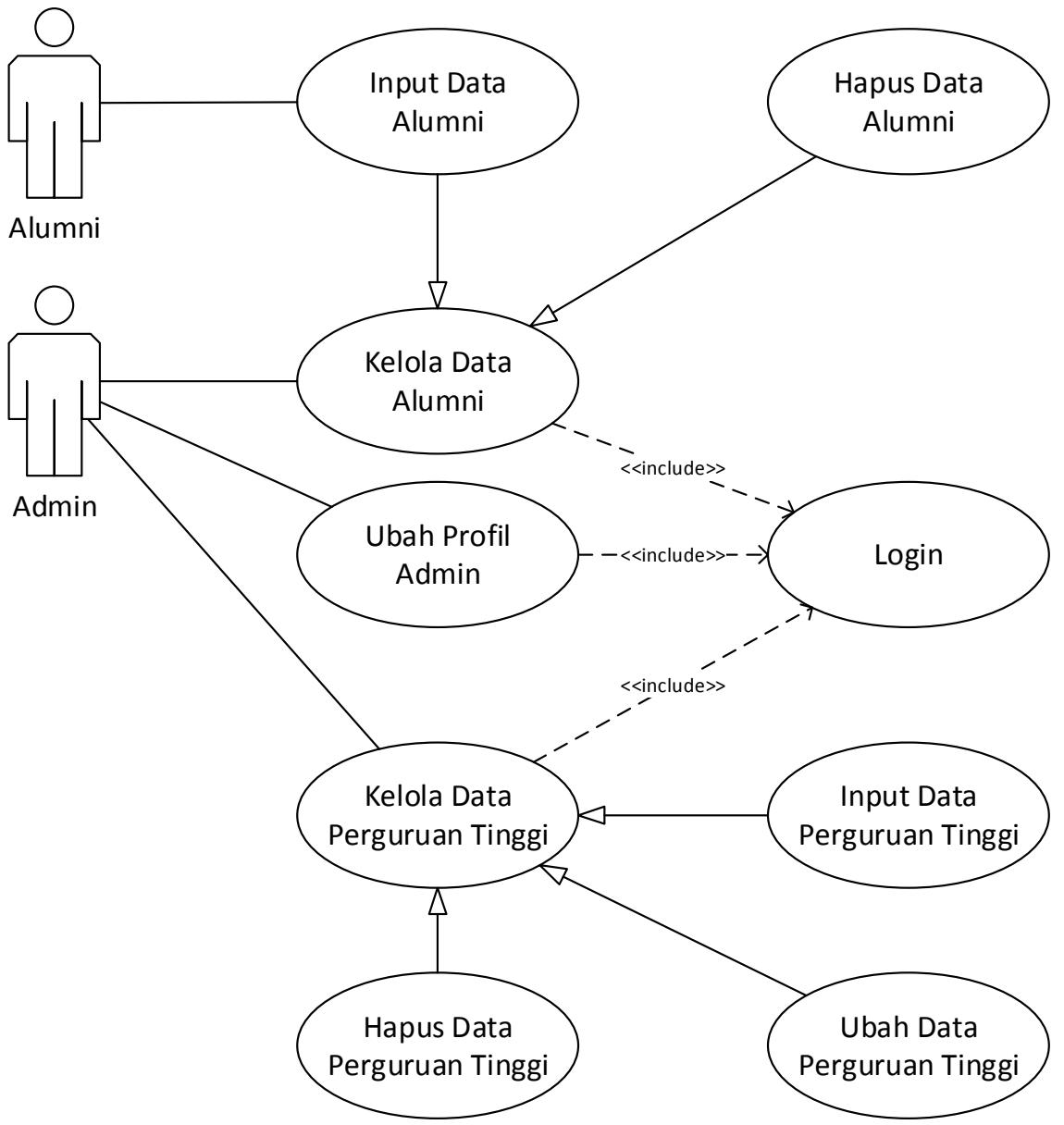

Gambar 2. Use case Aplikasi Pendataan Alumni SMA Negeri 6 Palembang

Berdasarkan diagram use case di atas, aplikasi pendataan alumni yang dikembangkan pada studi ini memiliki 2 aktor yang terdiri dari alumni dan admin. Admin dapat mengelola data alumni, mengubah profilnya sendiri, dan mengelola data perguruan tinggi. Dan admin wajib melakukan login ke dalam sistem untuk melakukan pengelolaan data tersebut. Sementara alumni hanya memiliki akses untuk menginput data pribadinya sebagai alumni.

\subsection{Custom Core System Class}

Core system class yang digunakan dalam studi ini merupakan core system class yang dibangun secara custom dengan mengikuti ketentuan yang ada dalam framework CodeIgniter. Secara custom, core system class yang dibangun dalam studi ini dimulai dari pengembangan custom model untuk kebutuhan CRUD. Custom model tersebut terdapat pada Gambar 3. 


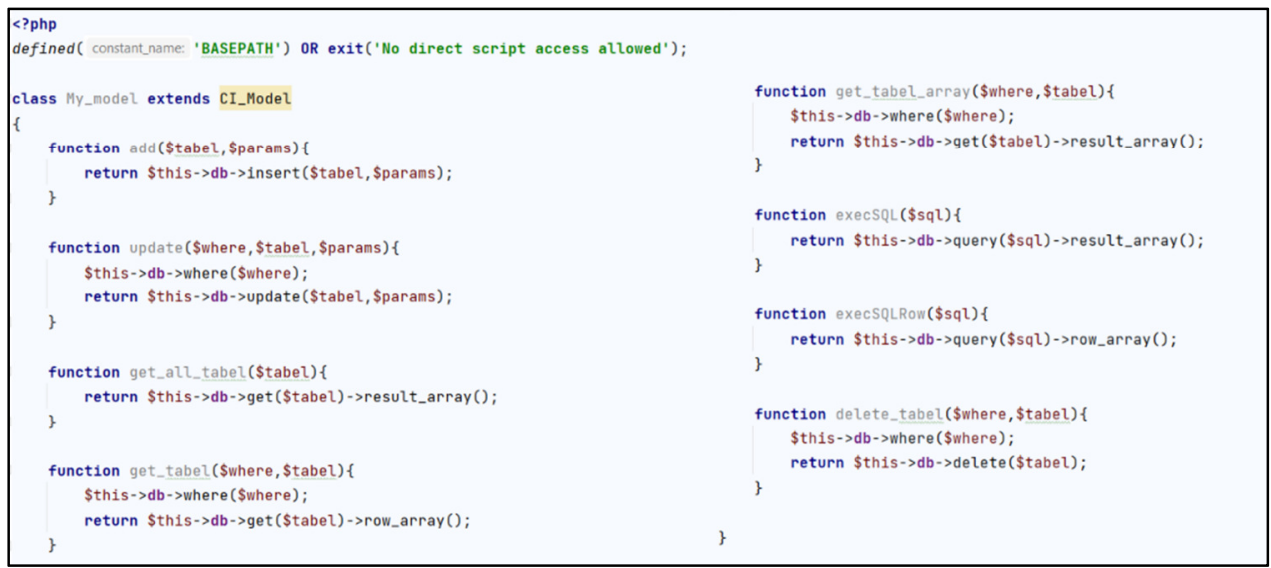

Gambar 3. Custom model

Selanjutnya, custom core system class dengan nama MY_Controller dibangun dengan memanfaatkan custom model yang telah dibuat sebelumnya pada Gambar 3. Custom core system class tersebut terdapat pada Gambar 4.

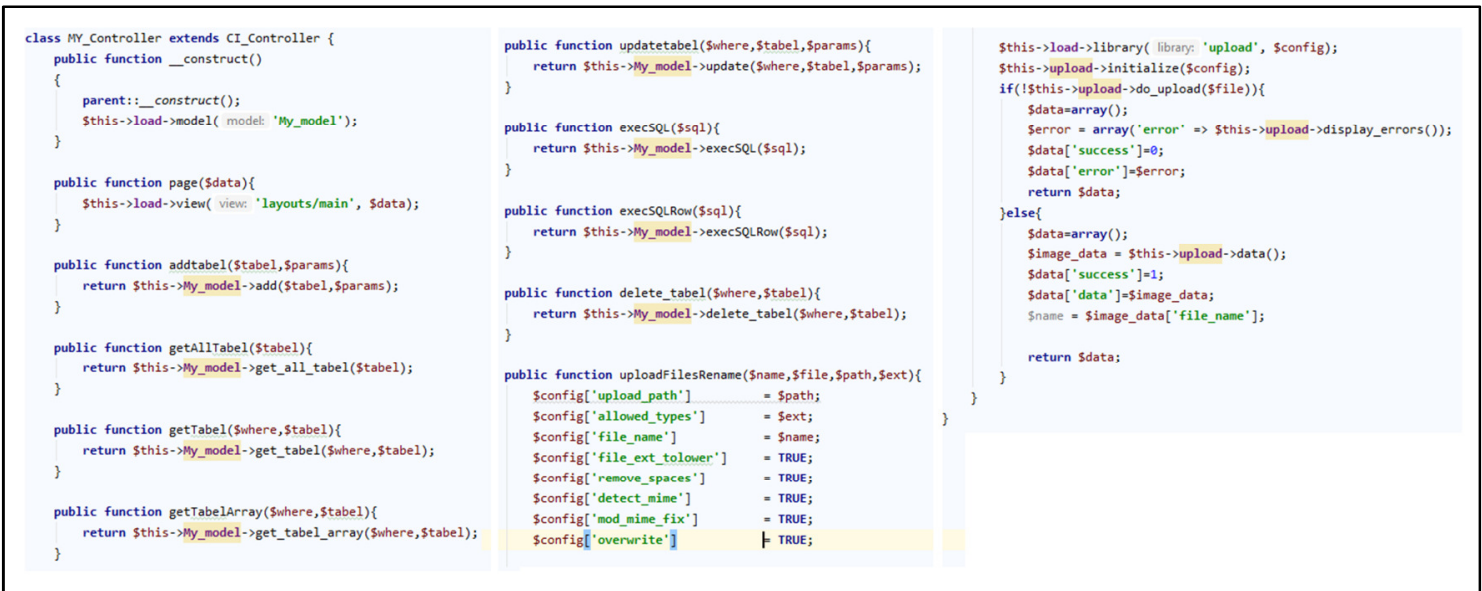

Gambar 4. Custom core system class

Setelah custom core system class dibangun, dilakukan pemanggilan method yang ada pada kelas MY_Controller dengan cara yang tertera pada Tabel 1 sebagai berikut.

Tabel 1. Penggunaan Method Dari Custom Core System Class

\begin{tabular}{|l|l|c|}
\hline \multicolumn{1}{|c|}{ Pemanggilan Method } & \multicolumn{1}{|c|}{ Kegunaan } & \multicolumn{1}{|c|}{$\begin{array}{c}\text { Operasi } \\
\text { CRUD }\end{array}$} \\
\hline \$this->page(\$data) & Memanggil halaman view & - \\
\hline \$this->addtabel(\$tabel, \$params) & $\begin{array}{l}\text { Menyimpan data ke dalam tabel melalui } \\
\text { parameter nama tabel dan variabel- } \\
\text { variabel yang akan disimpan }\end{array}$ & Create \\
\hline Pemanggilan Method & \multicolumn{1}{|c|}{ Kegunaan } & $\begin{array}{l}\text { Operasi } \\
\text { CRUD }\end{array}$ \\
\hline
\end{tabular}

Farisi, et., al [Rancang Bangun Aplikasi Pendataan Alumni SMA Negeri 6 Palembang Menggunakan CodeIgniter] 


\begin{tabular}{|l|l|l|}
\hline \$this->getAllTabel(\$tabel) & $\begin{array}{l}\text { Mengambil semua data dari tabel } \\
\text { tertentu tanpa kriteria where }\end{array}$ & Retrieve \\
\hline \$this->getTabel(\$where, \$tabel) & $\begin{array}{l}\text { Mengambil satu record data dari tabel } \\
\text { tertentu dengan kriteria where }\end{array}$ & Retrieve \\
\hline \$this->getTabelArray(\$where, \$tabel) & $\begin{array}{l}\text { Mengambil semua data dari tabel } \\
\text { tertentu dengan kriteria where }\end{array}$ & Retrieve \\
\hline $\begin{array}{l}\text { \$this->update_tabel(\$where, \$tabel, } \\
\text { \$params) }\end{array}$ & $\begin{array}{l}\text { Mengubah data dalam tabel dengan } \\
\text { kriteria dan variabel yang menjadi } \\
\text { parameter perubahan data }\end{array}$ & Update \\
\hline \$this->execSQL(\$sql) & $\begin{array}{l}\text { Mengambil semua data dari tabel } \\
\text { dengan struktur query yang rumit } \\
\text { seperti adanya operasi join terhadap } \\
\text { beberapa tabel }\end{array}$ & Retrieve \\
\hline \$this->execSQLRow(\$sql) & $\begin{array}{l}\text { Mengambil satu record data dari tabel } \\
\text { dengan struktur query yang rumit } \\
\text { seperti adanya operasi join terhadap } \\
\text { beberapa tabel }\end{array}$ & Retrieve \\
\hline \$this->delete_tabel(\$where, \$tabel) & $\begin{array}{l}\text { Menghapus data dari tabel } \\
\text { Mengunggah file ke server dengan } \\
\text { farameter nama file, file input dari } \\
\text { ekstensidari file yang diunggah. }\end{array}$ & Delete \\
\hline \$this->uploadFiles-Rename(\$name, dan \\
\$file, \$path, \$ext)
\end{tabular}

Gambar 5 dan Gambar 6 berikut ini adalah contoh penerapan custom core system class pada pengembangan aplikasi pendataan alumni SMA Negeri 6 Palembang yang digunakan dalam beberapa Controller.

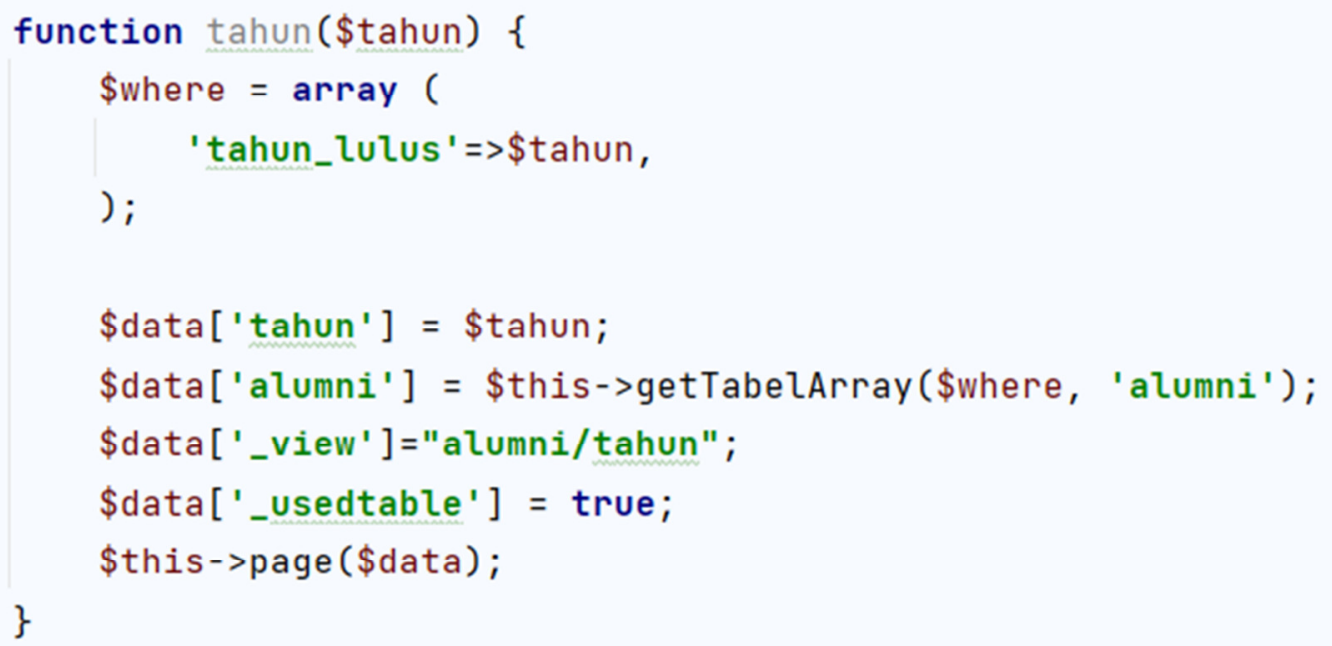

Gambar 5. Penerapan method \$this->page(\$data) dan \$this->getTabelArray(\$where, \$tabel) pada Controller Alumni 


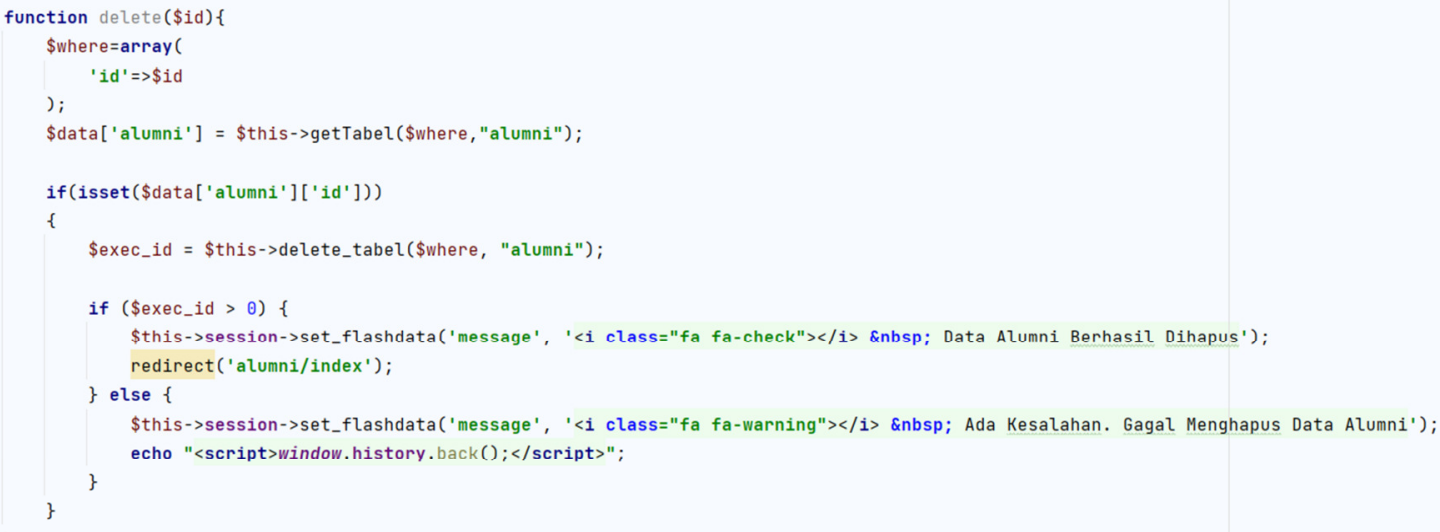

Gambar 6. Penerapan method \$this->delete_tabel(\$where, \$tabel) pada Controller Alumni

\subsection{Antar Muka Aplikasi}

Aplikasi pendataan alumni SMA Negeri 6 Palembang dikembangkan dengan metode kanban dalam pendekatan Agile Development Cycle. Hasil dari pengembangan aplikasi terdapat pada antar muka sistem pada Gambar 7, Gambar 8, Gambar 9, Gambar 10, dan Gambar 11 sebagai berikut.

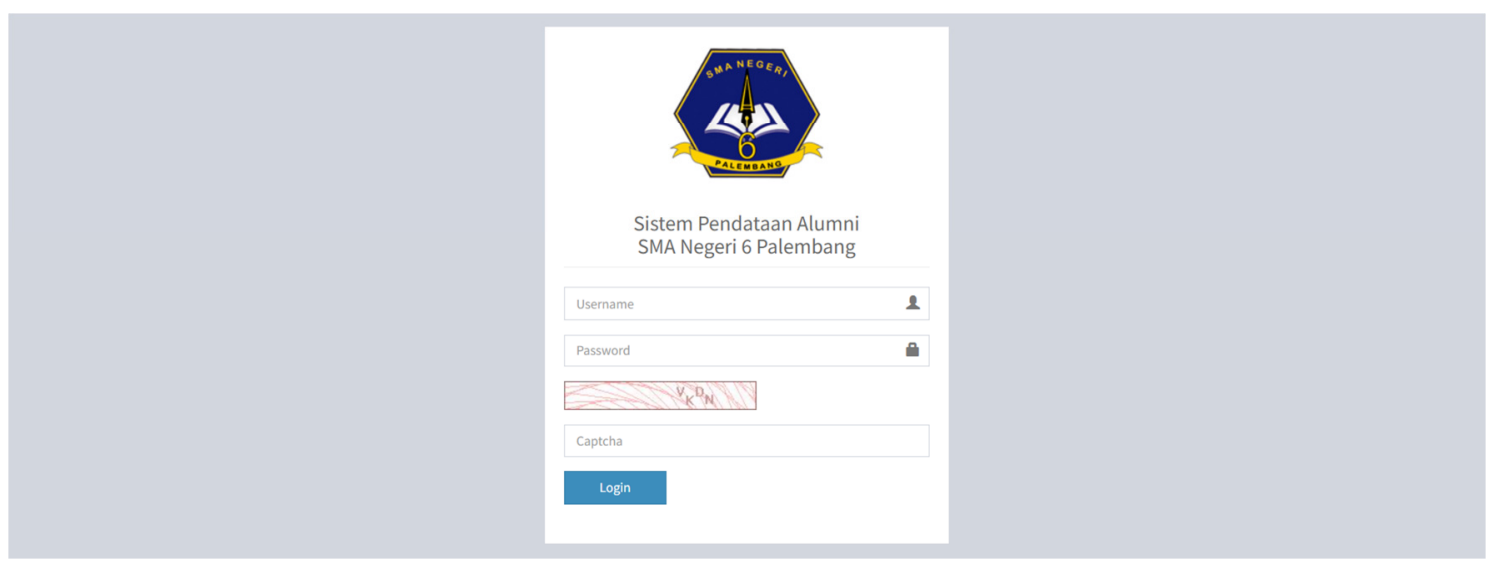

Gambar 7. Antar Muka Halaman Login Bagi Admin 


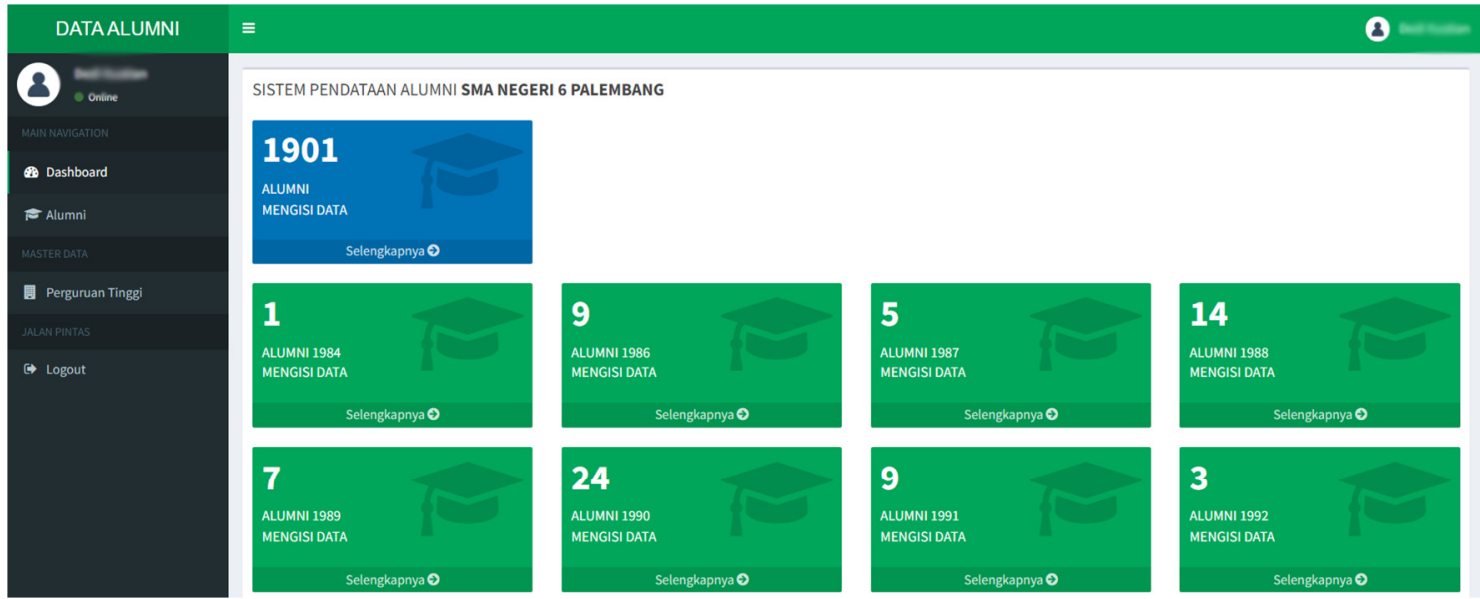

Gambar 8. Antar Muka Halaman Dashboard Bagi Admin

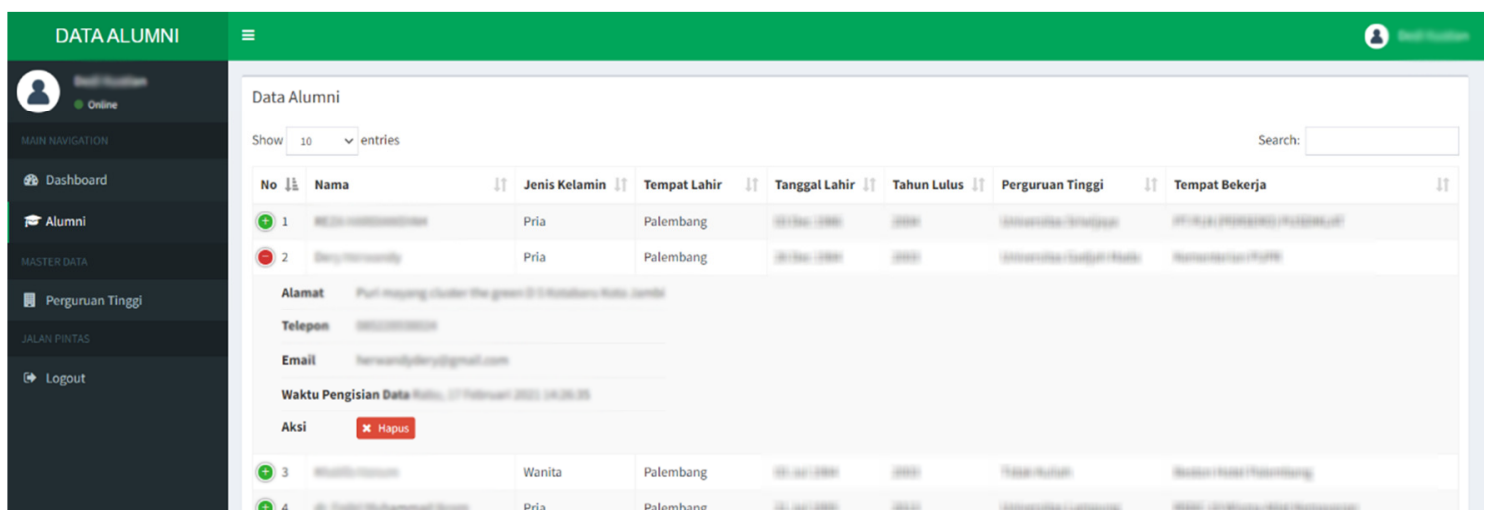

Gambar 9 Antar Muka Halaman Kelola Data Alumni Bagi Admin

\begin{tabular}{|c|c|c|c|c|c|}
\hline DATAALUMNI & $\equiv$ & & \multicolumn{3}{|c|}{$8=$} \\
\hline (2) monthe & Data Perguruan Tinggi & & \multicolumn{3}{|c|}{+ tamban } \\
\hline Manavection & Show $10 \quad v$ entries & \multicolumn{4}{|c|}{ Search: } \\
\hline ๑ Dasshoord & No II Nama Perguruan Tinggi & It Kota & If $\mathrm{Ak}_{\mathrm{s}}$ & ksi & it \\
\hline$=$ Alumni & Universitas Godjah Mada & Yogaganate & \multicolumn{3}{|c|}{ 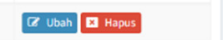 } \\
\hline mastreosita & Universitas Indonesia & Jakanta & \multicolumn{3}{|c|}{ 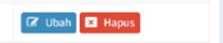 } \\
\hline D Perguruan Tingei & Universitas Sumatere Utara & Medan & \multicolumn{3}{|c|}{$\square$ Uash $\square$ Havous } \\
\hline MuNPWTIS & Universitas Airlangga & Surbaye & \multicolumn{3}{|c|}{ Co uant 口 raves } \\
\hline$\leftrightarrow$ Logout & Universitas Hasanudin & Makassar & \multicolumn{3}{|c|}{ 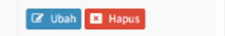 } \\
\hline & Universitas Andalas & Padang & \multicolumn{3}{|c|}{ 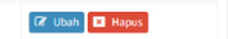 } \\
\hline & Universitas Padjadjaran & Bandung & \multicolumn{3}{|c|}{8 uaan 0 нavous } \\
\hline
\end{tabular}

Gambar 10. Antar Muka Halaman Kelola Data Perguruan Tinggi Bagi Admin 


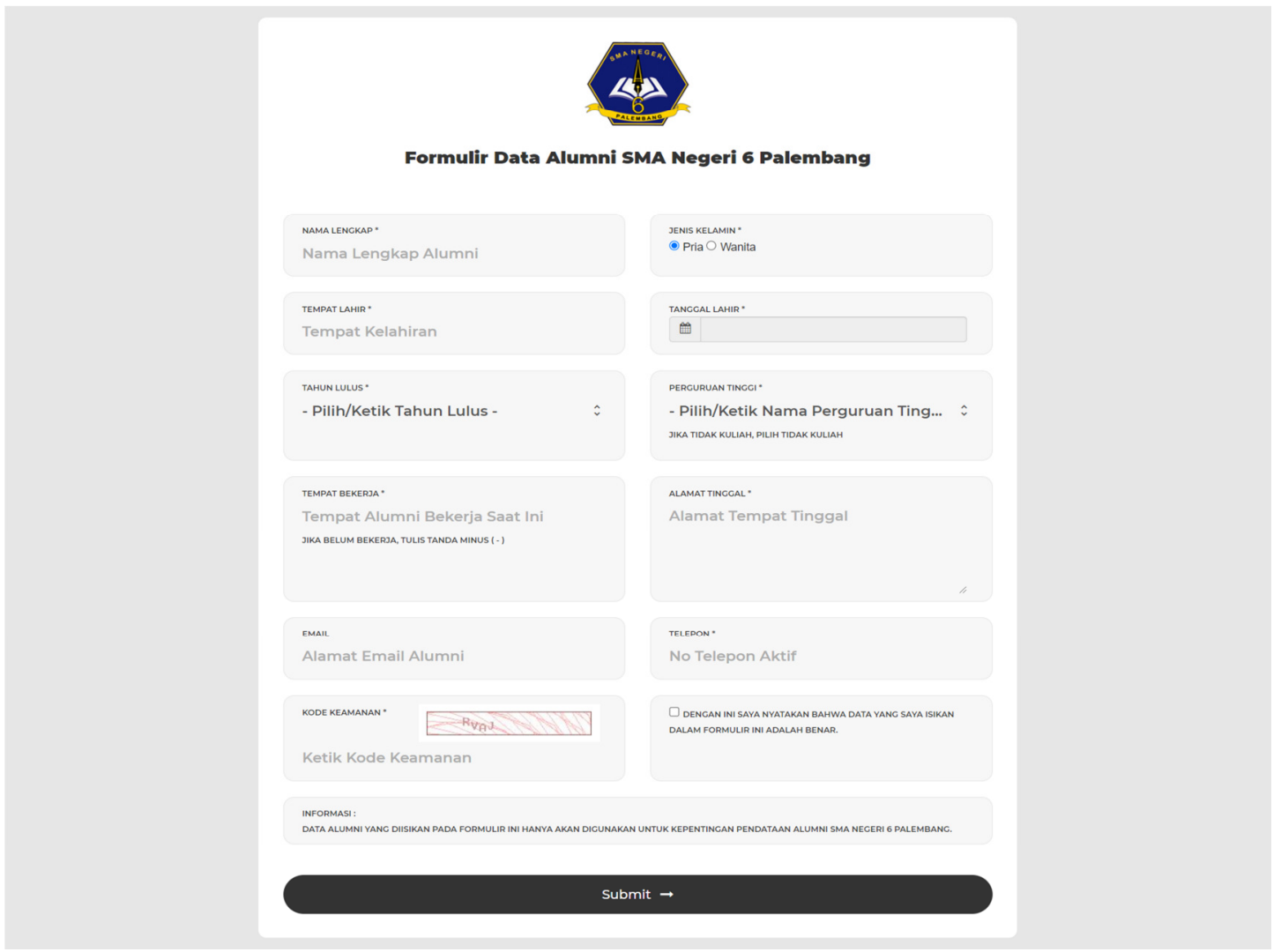

Gambar 11. Antar Muka Halaman Pengisian Data Alumni Bagi Alumni

\subsection{Webuse Method}

Bagian akhir dari studi ini adalah melakukan evaluasi terhadap aplikasi sistem pendataan alumni yang telah dikembangkan. Evaluasi ini dilakukan dengan menggunakan webuse method. Kuesioner Computer Usability Satisfaction Questionnaires yang merupakan bagian dari webuse method telah disebarkan kepada 30 orang responden pengguna sistem dari pengguna alumni dan 5 orang responden pengguna sistem dari admin. Kuesioner ini berisikan 19 pertanyaan dengan alternatif jawaban yang dibagi antara responden alumni dan responden admin. Alternatif jawaban 1 sampai 7 digunakan untuk responden alumni yang menunjukkan skala sangat tidak setuju (1) hingga sangat setuju (7). Sementara alternatif jawaban 1 sampai 5 digunakan untuk responden admin yang menunjukkan skala sangat tidak setuju (1) hingga sangat setuju (5). Hasil kuesioner selanjutnya dipetakan per jawaban kuesioner sehingga menghasilkan skor penelitian yang dapat dilihat pada Tabel 2 dan Tabel 3 sebagai berikut.

Tabel 2. Skor Penelitian Berdasarkan Webuse Method Dengan Responden 30 Orang Alumni

\begin{tabular}{|c|r|r|}
\hline Nilai & $\begin{array}{c}\text { Jumlah } \\
\text { Penilaian }\end{array}$ & Skor Penelitian \\
\hline 1 & 0 & 0 \\
\hline 2 & 0 & 0 \\
\hline 3 & 0 & 0 \\
\hline 4 & 112 & 448 \\
\hline 5 & 183 & 915 \\
\hline
\end{tabular}




\begin{tabular}{|r|r|r|}
\hline 6 & 130 & 780 \\
\hline 7 & 145 & 1015 \\
\hline & JUMLAH & $\mathbf{3 1 5 8}$ \\
\hline
\end{tabular}

Tabel 3. Skor Penelitian Berdasarkan Webuse Method Dengan Responden 5 Orang Admin

\begin{tabular}{|c|c|c|}
\hline Nilai & Jumlah Penilaian & Skor Penelitian \\
\hline 1 & 0 & 0 \\
\hline 2 & 0 & 0 \\
\hline 3 & 0 & 0 \\
\hline 4 & 24 & 96 \\
\hline 5 & 53 & 265 \\
\hline & JUMLAH & 361 \\
\hline
\end{tabular}

Berdasarkan Tabel 2 dan Tabel 3, skor hasil penelitian yang didapatkan adalah 3158 untuk responden alumni dan 361 untuk responden admin. Sementara skor tertinggi yang diharapkan adalah 3990 untuk responden alumni dan 475 untuk responden admin. Skor tertinggi yang diharapkan tersebut didapatkan dari hasil perkalian jumlah responden (30 untuk responden alumni dan 5 untuk responden admin), skala penilaian tertinggi ( 7 untuk responden alumni dan 5 untuk responden admin), dan jumlah pertanyaan (19). Berdasarkan skor-skor tersebut, didapatkan nilai usability (x) 0,79 untuk responden alumni dan nilai usability $(x)$ 0,76 untuk responden admin. Nilai usability $(x)$ didapatkan dari pembagian skor hasil penelitian dan skor tertinggi yang diharapkan. Nilai $x$ yang telah diperoleh selanjutnya diinterpretasikan ke dalam bentuk predikat sesuai Tabel 4 .

Tabel 4 Interpretasi Nilai Usability $(x)$

Kedalam Bentuk Predikat [12]

\begin{tabular}{|c|l|}
\hline Nilai Usability $(\boldsymbol{X})$ & \multicolumn{1}{|c|}{ Predikat } \\
\hline $0,0<x \leq 0,2$ & Sangat Buruk \\
\hline $0,2<x \leq 0,4$ & Buruk \\
\hline $0,4<x \leq 0,6$ & Cukup \\
\hline $0,6<x \leq 0,8$ & Baik \\
\hline $0,8<x \leq 1,0$ & Sangat Baik \\
\hline
\end{tabular}

Berdasarkan Tabel 4, nilai usability ( $x$ ) 0,79 untuk responden alumni dan 0,76 untuk responden admin dapat diinterpretasikan ke dalam bentuk predikat baik karena berada pada rentang 0,6 $<x \leq 0,8$. Hal ini menunjukkan bahwa dari sudut pandang usability, baik menurut alumni maupun menurut admin, aplikasi yang sistem pendataan alumni SMA Negeri 6 Palembang yang dikembangkan pada studi ini memberikan hasil yang baik.

\section{KESIMPULAN}

Setelah melakukan perancangan dan pembangunan aplikasi pendataan alumni SMA Negeri 6 Palembang, kesimpulan yang didapatkan dari studi ini adalah aplikasi pendataan alumni SMA Negeri 6 Palembang yang dibangun pada platform web dengan menggunakan custom core system class pada framework CodeIgniter dapat melakukan pengelolaan data alumni yang meliputi data-data identitas, data pendidikan, dan data pekerjaan alumni. 
Selanjutnya, berdasarkan evaluasi sistem yang dilakukan dengan menggunakan webuse method, aplikasi pendataan alumni SMA Negeri 6 Palembang ini menunjukkan nilai usability 0,79 untuk responden alumni dan nilai usability 0,76 untuk responden admin. Kedua nilai usability tersebut diinterpretasikan ke dalam bentuk predikat dan menunjukkan predikat baik.

\section{SARAN}

Aplikasi pendataan alumni SMA Negeri 6 Palembang yang telah dibangun dalam studi ini akan lebih baik dikembangkan lagi dengan fitur-fitur lainnya, seperti alumni diberikan akun untuk akses ke dalam aplikasi, sehingga apabila terdapat perubahan data alumni seperti domisili, pekerjaan, dan lain-lain, data akan selalu dapat selalu diperbarui oleh alumni secara mandiri.

\section{UCAPAN TERIMA KASIH}

Penulis mengucapkan terima kasih kepada SMA Negeri 6 Palembang yang telah memberikan kesempatan dan izin untuk dilakukannya publikasi dari studi yang telah dilaksanakan ini.

\section{DAFTAR PUSTAKA}

[1] L. A. Latif dan R. Bahroom, 2010, “OUM's Tracer Study: A Testimony to a Quality Open and Distance Education," ASEAN J. Open Distance Learn., Vol. 2, No. 1, hal. 35$47,$.

[2] S. E. Rahma dan A. D. Indriyanti, 2016. "Rancang Bangun Sistem Informasi Alumni Berbasis Web," J. Manaj. Inform., Vol. 6, No. 1, hal. 143-150,

[3] W. Amin, 2021. "Selamat Datang di SMA Negeri 6 Palembang," https://sman6plg.sch.id/about (diakses Jul 15, 2021).

[4] F. A. Riadi, 2021. "Perancangan Sistem Informasi Data Alumni (Studi Kasus: SMK Muhammadiyah Cerenti)," J. Perencanaan, Sains, Teknol. dan Komput., Vol. 4, No. 1, hal. 382-388,

[5] Wirna Apriliani, 2020, "Perancangan Sistem Informasi Pendataan Alumni SMA N 1 Kuantan Mudik Berbasis Web," J. Perencanaan, Sains, Teknol. dan Komput., Vol. 3, No. 1, hal. 136-147, [Daring]. Tersedia pada: www.journal.uta45jakarta.ac.id.

[6] Ariansyah, Fajriyah, dan F. S. Prasetyo, 2017. "Rancang Bangun Sistem Informasi Pendataan Alumni Pada Stie Prabumulih Berbasis Website Dengan Menggunakan Bootstrap,” J. Mantik Penusa, Vol. 1, No. 2, hal. 26-30,

[7] A. Farisi, 2021. "Pengembangan Aplikasi Tanda Tangan Digital Dengan Metode Hash Menggunakan Custom Core System Class pada Framework CodeIgniter The Development of Digital Signature Application with Hash Method Using Custom Core System Class on CodeIgniter Framework," J. JTSI, Vol. 2, No. 1, hal. 137-149, 
[8] A. Farisi, K. Achmad Siddik, A. Algharizah, dan Handri, 2020, "Penerapan Custom Core System Class pada Pengembangan Sistem Informasi Manajemen Donasi The Implementation of Custom Core System Class in The Development of Donation Management Information System," JTSI, Vol. 1, No. 1, hal. 95-105, [Daring]. Tersedia pada: http://jurnal.mdp.ac.id/index.php/jtsi/article/view/327.

[9] E. Utami, J. E. Istiyanto, dan S. Raharjo, 2007. "Metodologi Penelitian pada Ilmu Komputer,” Semin. Nas. Teknol. 2007, Vol. 2007, No. November, Hal. 1-13,

[10] K. Graham, 2016. "Tech Matters : Getting on the 'Kanban' - wagon: Using Kanban Flow for Time and Project Management,” LOEX Conf. Proc., Vol. 43, Hal. 4-7,

[11] E. F. India, 2019. "How To Use Agile Kanban Methodology In Software Development Service?,” medium.com, https://medium.com/@ExpertsFromIndia/how-to-use-agilekanban-methodology-in-software-development-service-9d7006049965 (Diakses Mar 04, 2021).

[12] T. K. Chiew dan S. S. Salim, 2003 "Webuse: Website Usability Evaluation Tool," Malaysia J. Comput. Sci., Vol. 16, No. 1, Hal. 47-57,.

[13] R. S. Pressman, 2014. Software Quality Engineering: A Practitioner's Approach, Seventh Ed., Vol. 9781118592. McGraw-Hill, New York. 